http://jmscr.igmpublication.org/home/

ISSN (e)-2347-176x ISSN (p) 2455-0450

crossref DOI: https://dx.doi.org/10.18535/jmscr/v7i12.123

Journal Of Medical Science And Clinical Research

\title{
Caesarean Section: Review at Full Dilation and Fetomaternal Outcome
}

\author{
Authors \\ Dr Rajkishori Dandotiya ${ }^{1}$, Dr Paribhashita Mishra ${ }^{2}$ \\ ${ }^{1}$ Assistant Professor, Dept of Obs and Gynaecology, Gajara Raja Medical College, Gwalior, MP, India \\ ${ }^{2}$ Associate Professor, Dept of Obs and Gynaecology, Gajara Raja Medical College, Gwalior, MP, India \\ *Corresponding Author
}

Dr Paribhashita Mishra

Associate Professor, Dept of Obs and Gynaecology, Gajara Raja Medical College, Gwalior, MP, India

\section{Introduction}

In 1954 Friedmann narrated different curves for progress of labour in multiparous and nulliparous females. Any divergence is failure to progress ${ }^{(1)}$. In 1969 active management of labour was introduced to decrease the caesarean rate. ${ }^{(2)}$ Various surgical, medical and instrumental interventions are described when there is arrest in second stage of labour ${ }^{(3)}$

\section{Methodology}

In this study the objective was to decide the indication of caesarean section and fetomaternal outcome. It is a retrospective study of 2 years at Kamla Raja Hospital, Gajara Raja Medical College with-

\section{Inclusion Criteria}

1) Singleton pregnancy irrespective of gravidae

2) Period of gestation $>37$ weeks with presentation being cephalic

\section{Exclusion Criteria}

Twins, preterm and other comorbid conditions.

\section{Results}

PTS studied were 6200 in 2 years. Average maternal age was 24.75 years of which 200 caesarean section were done at full dilation. Induction of labour was done in $68 \%$ Gestational age of these patients were 37-40 weeks with postdatism being ....Most common cause of caesarean section was CPD $45 \%$ and fetal distress $25 \%$.

Technique by which deeply engaged head was delivered was:

\begin{tabular}{|l|c|c|}
\hline Technique & Number & percentage \\
\hline Vertex & 110 & $55 \%$ \\
\hline Patwardhan & 65 & $32.5 \%$ \\
\hline Push & 25 & $12.5 \%$ \\
\hline
\end{tabular}

Labour was induced in $68 \%$ patients and $32 \%$ patients had spontaneous labour. Indication of Caesarean section

\begin{tabular}{|l|c|c|}
\hline & Number & $\%$ \\
\hline CPD & 90 & $45 \%$ \\
\hline Fetal distress & 50 & $25 \%$ \\
\hline NPOL & 22 & $11 \%$ \\
\hline Persistent occipito posterior & 16 & $8 \%$ \\
\hline Deep Transverse Arrest & 12 & $6 \%$ \\
\hline Failed Instrumentation & 10 & $5 \%$ \\
\hline
\end{tabular}

Patients had more than one indication so total number does not match with above result .Vaccum 
application in $20 \%$ and failed following which emergency caesarean section performed.

\begin{tabular}{|l|c|c|}
\hline Maternal complications & No & $\%$ \\
\hline $\begin{array}{l}\text { Atonic PPH medical } \\
\text { management }\end{array}$ & 10 & $05 \%$ \\
\hline Surgical management & 05 & $2.5 \%$ \\
\hline Postoperative fever & 24 & $12 \%$ \\
\hline Uterine incision extension & 20 & $10 \%$ \\
\hline Haematuria & 30 & $15 \%$ \\
\hline Component transfusion & 03 & $1.5 \%$ \\
\hline $\begin{array}{l}\text { Wound infection requiring } \\
\text { resuturing }\end{array}$ & 05 & $2.5 \%$ \\
\hline
\end{tabular}

Maternal mortality was present owing to post partum haemorrhage and severe anaemia as patient was referred from periphery at late stage .PPH was present in 15 patients out of which 10 were medically mananged and 5 were surgically managed. These tears which were present in lower uterine segment were extensions, broad ligament haematoma or avulsion of uterine artery. Bladder was high up in many accounting for haematuria in 30 cases and pyrexia in $24 \%$. Component transfusion was required in 3 cases. Majority babies weighed between 2.5 to $3.5 \mathrm{~kg}$.NICU admission was 29 Apgar $<7$ at 5 minutes 13 .

\section{Fetal \& Neonatal Complications}

\begin{tabular}{|l|c|c|}
\hline & Number & $\%$ \\
\hline Fresh still birth & 1 & $0.5 \%$ \\
\hline Cephalhaematoma & 2 & $1 \%$ \\
\hline NICU admissions & 29 & $14.5 \%$ \\
\hline Neonatal jaundice & 11 & $5.5 \%$ \\
\hline Apgar <7 at 5 min & 13 & $6.5 \%$ \\
\hline Meconium stained liquor & 10 & $5 \%$ \\
\hline Neonatal death & 1 & $0.5 \%$ \\
\hline
\end{tabular}

\section{Discussion}

Last three decades have seen an increase in second stage arrest $^{(4)}$. In our study primigravidae had more rate of caesarean section in second stage as compared to first stage owing to rigid perineum, cephalopelvic disproportion and lack of experience. This study was similar to Feinstein ${ }^{(4,5)}$. With prolongation of second stage, there is distension of lower segment which keeps thinning out and then vertex becomes more impacted in pelvis. This increase the operative time and increase the need of applying Patwardhan's technique and other technique. This causes an extension of uterine incision which in our case was $20 \%$. Owing to inflation of second stage there is increased atonic $\mathrm{PPH}^{(6)}$. In our study $\mathrm{PPH}$ was there in 15 patients. Shalha Baloch ${ }^{(4,5)}$ had $12 \%$ PPH. , 5.4\% extension of uterine incision. In our study Patwardhans manouvre was applied in 65 cases similar to the observation by Shalha Baloch. In our cases caesarean section causes were commonly due to cephalopelvic disproportion (45\%) followed by fetal distress (25\%) nonprogress of labour (11\%). This data was coherent with David G and Untersheider ${ }^{(6,7)}$. Post operative fever was present in $24 \%$. Which was lower than study by Baloch and Babre ${ }^{(8,9)}$ accounting for $33 \%$. This caused an increment in the number of hospital stay of patients .

In our study NICU admission rate was 22-29\%. This is consistent with the study by David $G^{(6)}$. The reason was mainly due to neonates requiring sepsis screening and parentral antibiotics administration. Neonatal death was one and fresh still birth was one which was lesser than that reported by Umbeli ${ }^{(10)}$. Our study revealed 13 babies with Apgar $<7$ at 5 minutes similar to study by Umbeli. As our study was retrospective in nature, therefore suggestion are to be taken with caution. Presence of caput, moulding and asyncytilism had poor documentation.

\section{Conclusion}

A senior obstetrician is required to determine suitable decisions as regards to trial or caesarean section in full dilation. Adequate supervision and skill improvement will minimize morbidity and mortality in second stage caesarean section and fetomaternal outcome. Proper partogram, pain relievers, labour augmentation and all effective techniques to deal with shoulder dystocia, Patwardhan and other techniques should be implemented.

\section{References}

1. Friedmann EA. The graphic analysis of labor. Am Journal Obstet Gynaecol. 1954;68:1568-75 
2. Olah KJS. Failure to progress in the management of second stage of labour . $\mathrm{Br}$ J Obstet Gynaecol.1994;101:1-3.

3. Cardozo LD,Gibb DMF, Studd JWW et al. Predictive value of cervimetric labor patterns in primigravidae $\mathrm{Br} \mathrm{J}$ Obstet Gynaecol .1982;89:33-8

4. Feinstein U, Sheiner E, Levy A, Hallak M, Mazor M . Risk factors for descent during second stage of labour .Int $\mathbf{J}$ Gynaecol Obstet2002;77(1) :7-14.

5. Baloch S, Khaskheli $M$. Frequency of second stage intervention and its outcome in relation with instrumental vaginal delivery versus caesarean section . J Ayub Med Coll Abbottabad .20082008; 20(1):87-90.

6. David G, Fleming T, Ford K et al (2015). Caesarean section at full dialation. Aust NZ J Obstet and Gynaecol.55(6):565-571

7. Unterscheider J, Mc Menamin M, Cullinane (2011) Rising rates of caesarean deliveries at full dialation : a concerning trend .Eur J Obstet. Gynecol.Reprod Biol. 157 (2): 141 -144

8. Babre VM, Bendre KR ,Niyogi G (2017). Review of caesarean sections at full dialation .Int J Reprod Contracept Obstet. Gynecol.6 (6):2491-2493.

9. Umbeli T, Sahal Ismail et al. Maternal and neonatal complications associated with caesarean section in the second stage of labour at Omdurman maternity hospital during 2012-13. Merit Research Journal of Medicine and Medical Sciences. 2014 ;2(10) :225-8. 